\title{
INFLUENCE OF THE TELEVISION PROGRAM “AULA365” IN THE LEARNING OF CHILDREN
}

\author{
Edward Enrique Rojas de la Puente \\ Toribio Rodríguez de Mendoza National University of Amazonas, Peru \\ José Walter Coronel Chugden \\ Toribio Rodríguez de Mendoza National University of Amazonas, Peru \\ Guido Ayay Arista \\ Toribio Rodríguez de Mendoza National University of Amazonas, Peru
}

\begin{abstract}
The objective of the research was to determine the influence of the interactive television program "Aula365" in the learning of children in the fourth grade of the primary level of the Educational Institution "Seminario Jesús María”, Chachapoyas-Peru; for this, the quasi-experimental research design called "design with pre and post test with non-randomized control group" has been used. The non-probabilistic sample consisted of 2 sections " $B$ " and " $C$ " of the fourth grade, one for the experimental group and one for the control group of 30 students each, whose average age was 9 years. The study had as an independent variable the interactive television program "Aula365" and dependent on the learning variable. The instrument used was the Barranquilla Rapid Test (BARSIT) consisting of 60 items with a single weight of 1 point each item, which determined the levels of the learning variable according to a scale of predetermined values by: very lower (0-9), inferior (9-18), normal (18-27), superior (27-31) and excellent (31-60). The hypothesis was contrasted by means of the statistical parameter T-Student for two independent samples, to evaluate the influence of the interactive television program "Aula365" on student learning with a 95\% probability of confidence. The results in the experimental group show that the T test was statistically significant (Tc $=4.076$, $p<0.05$ ), with an average of 28.4 in the pretest and 35.7 points in the post test, which evidenced an improvement in the learning of the kids; however, in the control group the Ttest was not statistically significant (Tc $=-1,147,0.95, p>0.05)$, with an average of 20.3 in the pretest and 20.1 in the post test. Finally, it is concluded that the interactive TV program "Aula365" positively influenced, since the children achieved an excellent learning.
\end{abstract}

Keywords: learning, primary education, influence, interaction, television program Aula365.

\section{Introduction}

Technological advances in the XXI century, are developed considerably and as a consequence, communication practices are consolidated from the media such as television, radio, Internet, among others, with excessive possibilities of influence in education. Chavez (2004) states that although the social function of television is, in broad strokes, to cultivate values and promote culture, it is not 
necessary to educate its viewers, but there are those who suggest that every program educates, only that - the same as school, the same as home - can educate right or wrong. In this context, within the media, television is the most accessible medium for children (Díaz, Enciso, González, Mendoza, \& Fonseca, 2019), since it is present in most homes and does not require complex skills to receive information, as it would be, for example to read, in the case of newspapers; Asencio (2012) states that television has both positive and negative influences on children, and it is important to analyze the influences and their effects in order to control the negative and promote the positive.

Researchers at the University of Pittsburgh and Harvard conducted a study on the habits of media consumption in 4142 healthy adolescents, and calculated that every additional hour of television watched per day increases the probability of being depressed by 8\%. (Cited by Pijamasurf, 2009). Because of its art, the most recent studies carried out in Colombia by Criado, Pallares, \& Ascanio (2019), in Mexico by Díaz, Enciso, González, Mendoza, \& Fonseca (2019) and in Peru by Martinez \& Ureta (2019) conclude that the television programs that students watch have a great influence on behavior and learning.

The above is corroborated in observational theory or learning by observation or modeling developed by Bandura (1984), who demonstrates that human beings acquire new behaviors without obvious reinforcement and even when they lack the opportunity to apply knowledge. The only requirement for learning may be that the person observes another individual, or model, to carry out a certain behavior. Later, especially if the model received a visible reward for its execution, the observer may also manifest the new response when given the opportunity to do so. (Ruiz, 2010). Bandura (1984), highlights how, between observation and imitation, cognitive factors intervene that help the subject to decide whether the observed is imitated or not. Observation and imitation in young children model parents, educators, friends and even television heroes.

Due to the importance of the subject, the present investigation was carried out, whose objective was to determine the influence of the interactive television program "Aula365" in the learning of fourth grade primary school children of an Educational Institution; For this purpose, as specific objectives, the evaluation of learning in the understanding of vocabulary through recognition of antonyms; evaluate learning related to verbal reasoning through the recognition of synonyms, evaluate the learning of logical reasoning according to its analogous reasoning and evaluate the learning of numerical reasoning through numerical series and finally, compare the learning progress in the control study groups and experimental. In this sense, a quasi-experimental investigation has been carried out, formulated in the following question: what extent does the interactive television program "Aula365" influence the learning of children in the fourth grade of primary school of an Educational Institution? Therefore, we have 
gathered the main approaches to television, in essence, the positive influences of educational-cultural television programs, in student learning. The general research hypothesis was formulated in the following terms: The interactive television program “Aula365” positively influences student learning, the results of which are described below.

\section{Methodology}

Population and simple. The population was determined by 75 students of the fourth grade of primary education of the Educational Institution "Seminario Jesús María”, of the city of Chachapoyas-Peru, enrolled in the 2018 school year. However, to select the sample a sample was used by convenience, considering 2 sections: fourth grade "C" with 30 students for the control group and fourth grade "B" with 30 students for the experimental group, whose average age was 9 years.

Design of the investigation. The quasi-experimental design called "pre and post test design with a non-randomized control group” (Ñaupas, Mejía, Novoa, \& Villagómez, 2013, p. 282) has been used.

Research instrument. The instrument used in the research process and with its respective measurement scale was: the Barranquilla Rapid Test (BARSIT) (Del Olmo, 1958) consisting of 60 items, which has a single weight each item of 1 point the correct one and 0 incorrect, hence it determines the levels of learning according to a scale of predetermined values of much lower (0-9), lower (9-18), medium or normal (18-27), higher (27-31) and excellent (31-60). The Barranquilla Rapid Test is a test that evaluates the learning of the person associated with their general intelligence, and is composed of 60 items that evaluate five dimensions: 1 . Items that measure information or general knowledge acquired. 2. Understanding vocabulary: through recognition of opposites. 3. Verbal reasoning: is to discriminate a word that expresses a different category from others. They are 4 words that have equal category. 4 . Logical reasoning: the association with a given element of its analogue, in accordance with an already known association principle; For example, the chair is for sitting, the bed is for... and 5. Numerical reasoning: an operation in which series of numbers are given that must be completed once the rule governing each series is deducted. With the exception of the numerical series, the other four are formulated with the multiple choice system.

Job overview. Initial phase: The purpose of the study was presented and socialized and consent was requested, then the pre-test was applied to both groups, constituted by the Barranquilla Rapid Test (Del Olmo, 1958).

Intermediate phase: 10 learning sessions were applied to the experimental group; Each session was planned for students in the fourth grade of the elementary 
level in a time of 90 minutes, whose subjects were obtained from the Aula365 Interactive Television Program, downloaded from the official website of the YouTube channel dedicated to teaching (main website https://www.youtube. com/user/aula365tv).

The Aula365 television program was created in 2007 by Professor Pablo Aristizabal in the country of Argentina. Aula365 stimulates collaborative intelligence, favors the learning process and motivates learning through a social platform based on participation and collaboration in a safe environment. Through a series of multimedia and interactive content and with its own pedagogical model, all classified by age and grades, Aula365 brings parents and children together in an innovative teaching-learning process. Aula365 currently has more than 3 million users, including students, parents and teachers from Argentina, Chile, Peru, Uruguay, Mexico, Colombia, Italy, Spain, Brazil and the United States (World Summit Award, 2013).

The downloadable videos of the channel, have as subtitle: "Educational videos for children". The interactive educational programs downloaded and applied to the experimental group were the following:

1. How to use punctuation marks

2. Own and common nouns

3. How are verbs conjugated

4. Synonyms, antonyms and paronyms

5. Can you guess all the series

6. World maps: physical map and political map

7. How much do you know about math? Multiplication, division, fractions, angles

8. How to add and subtract fractions?

9. How to add and subtract with numerical scales

10. The geometric figures

The themes were developed through the workshop technique, through videos. Each video on average has a duration of seven to ten minutes, so the remaining time is spent interacting on the topic presented and in the resolution of application activities and practices.

The 10 videos chosen and with which the learning sessions were planned, obey the five dimensions that the Barranquilla rapid test evaluates.

Final phase: The post test was applied to both control and experimental groups, constituted by the Barranquilla Rapid Test (BARSIT).

To statistically assess the results, we have operated with the contrasted differences in each group between the pre test and the post test. To these differences the statistical parameter T-Student has been applied, with a significance level of 0.05 or 5\% and a confidence level (Z): 1.96 (95\%). Finally, 
the statistical hypothesis was contrasted, deciding whether the hypothesis (H0) is accepted or rejected based on the comparison of the calculated $\mathrm{T}$ and tabulated $\mathrm{T}$.

Finally, the processing and tabulation of the information obtained from the pre test and post test of the sample under study, was carried out with the help of the Microsoft Excel 2013 spreadsheet and the statistical software SPSS V.23.0.

\section{Results of the research}

In table 1 , the averages obtained from the pre and post test in the control group in relation to the learning variable are analyzed, and it was found that in the pre test and post test $6.67 \%$ of the students, according to the learning scale they presented excellent and superior learning, without observing differences; This is due to the absence of stimulus in the control group; Likewise, it was found that of the 30 students evaluated in the control group, in the pre-test, $46.7 \%$ presented normal learning and in the post-test it amounted to 50\%. Similarly, 36.6\% in the pre-test and $30 \%$ in the post-test, presented a learning below the scale and only $3.33 \%$ in the pre-test and $6.66 \%$ in the post-test presented a learning much lower than the scale.

Table 1 Learning of the control group students in the pre and post test

\begin{tabular}{|ccccc|}
\hline \multirow{2}{*}{ Learning scale } & \multicolumn{2}{c}{ Pre test } & \multicolumn{2}{c|}{ Post test } \\
\cline { 2 - 5 } & $f_{i}$ & $\%$ & $f_{i}$ & $\%$ \\
\hline Excellent (31-60) & 2 & 6.67 & 2 & 6.67 \\
Superior (27-31) & 2 & 6.67 & 2 & 6.67 \\
Normal (18-27) & 14 & 46.7 & 15 & 50.0 \\
Bottom (9-18) & 11 & 36.6 & 9 & 30.0 \\
Very lower (0-9) & 1 & 3.33 & 2 & 6.66 \\
\hline Total & 30 & 100 & 30 & 100 \\
\hline
\end{tabular}

Source: Pre test and post test of the control group.

Table 2 shows the difference in averages obtained in the experimental group before and after the application of the interactive television program Aula365 as a stimulus. The results of the pre-test determined that $23.3 \%$ of the students presented excellent learning, 53.4\% presented a higher learning, $23.3 \%$ a normal learning and no student was in a lower or much lower learning than normal; however, in the post test, after applying the interactive television program Aula365, the scores rose significantly, that is, all students achieved excellent learning, whose scores are in the range of 31 to 60, with marked differences one more What others; Therefore, it is clear that the use of educational-cultural programs such as Aula365 used as tools and teaching-pedagogical means, 
positively influence student learning, also reinforcing their skills, abilities, abilities and attitudes of learning.

Table 2 Student learning before and after stimulation in the experimental group

\begin{tabular}{|lcccc|}
\hline \multirow{2}{*}{ Learning scale } & \multicolumn{2}{c}{ Pre test } & \multicolumn{2}{c|}{ Post test } \\
\cline { 2 - 5 } & $f_{i}$ & $\%$ & $f_{i}$ & $\%$ \\
\hline Excellent (31-60) & 7 & 23.3 & 30 & 100 \\
Superior (27-31) & 16 & 53.4 & 0.0 & 0.0 \\
Normal (18-27) & 7 & 23.3 & 0.0 & 0.0 \\
Bottom (9-18) & 0 & 0.0 & 0.0 & 0.0 \\
Very lower (0 - 9) & 0 & 0.0 & 0.0 & 0.0 \\
\hline \multicolumn{1}{c}{ Total } & 30 & 100 & 30 & 100 \\
\hline
\end{tabular}

Source: Pre test and post test of the experimental group.

On the other hand, table 3 shows the difference in averages according to the dimensions of the learning variable in the experimental group before and after applying the interactive television program "Aula365". These dimensions correspond to the Barranquilla Rapid Test (BARSIT), which quickly assesses the learning of the person associated with their general intelligence. Consequently, as a result a clear difference was found in student learning of 7.33 points with respect to pre and post test. Likewise, in each of the dimensions of the learning variable, significant differences of 0.2 are shown in general knowledge, 2.2 in vocabulary comprehension, 1.8 in verbal reasoning, 1.5 in logical reasoning and 1.6 in numerical reasoning. Such averages quantitatively corroborate the influence of the interactive television program "Aula365" on student learning.

Table 3 Average learning scores in the students of the experimental group before and after applying the interactive television program "Aula365"

\begin{tabular}{|c|c|c|c|}
\hline Dimensions & Test & Average & Dif. Averages \\
\hline \multirow{2}{*}{ Student learning } & pre test & 28.40 & \multirow{2}{*}{7.33} \\
\hline & pos test & 35.73 & \\
\hline \multirow{2}{*}{ General knowledge } & pre test & 5.5 & \multirow{2}{*}{0.2} \\
\hline & pos test & 5.7 & \\
\hline \multirow{2}{*}{ Vocabulary comprehension } & pre test & 5.8 & \multirow{2}{*}{2.2} \\
\hline & pos test & 8 & \\
\hline \multirow{2}{*}{ Verbal reasoning } & pre test & 5.5 & \multirow{2}{*}{1.8} \\
\hline & pos test & 7.3 & \\
\hline \multirow{2}{*}{ Logic reasoning } & pre test & 5.8 & \multirow{2}{*}{1.5} \\
\hline & pos test & 7.3 & \\
\hline \multirow{2}{*}{ Numerical reasoning } & pre test & 5.8 & \multirow{2}{*}{1.6} \\
\hline & pos test & 7.4 & \\
\hline
\end{tabular}

Source: Pre test and post test of the experimental group. 
SOCIETY. INTEGRATION. EDUCATION

Proceedings of the International Scientific Conference. Volume IV, May $22^{\text {th }}-23^{\text {th }}, 2020.108-119$

Similarly, table 4 shows the difference in averages according to the dimensions of the learning variable in the control group. As you can see the differences in each of the dimensions were minimal or almost nil; since, all this is due to the fact that in the control group there was no presence of stimuli, that is, it was a control group that allowed us to compare the effect of the independent variable on the dependent one.

Table 4 Difference of averages in the pre and post test according to dimensions of the learning variable in the control group

\begin{tabular}{|lcc|}
\hline \multicolumn{1}{|c}{ Dimensions } & Test & Average \\
\hline \multirow{2}{*}{ Student learning } & pre test & 20.37 \\
& pos test & 20.07 \\
\hline \multirow{2}{*}{ General knowledge } & pre test & 4.07 \\
& pos test & 4.09 \\
\hline \multirow{2}{*}{ Vocabulary comprehension } & pre test & 4.08 \\
& pos test & 4.09 \\
\hline \multirow{2}{*}{ Verbal reasoning } & pre test & 4.07 \\
& pos test & 4.40 \\
\hline \multirow{2}{*}{ Logic reasoning } & pre test & 4.07 \\
& pos test & 4.40 \\
\hline \multirow{2}{*}{ Numerical reasoning } & pre test & 4.08 \\
& pos test & 3.09 \\
\hline
\end{tabular}

Source: Pre test and post test of the control group.

To determine the significance of the results, the hypothesis was contrasted using the T-Student statistical parameter for two independent samples, to evaluate the influence of the interactive television program "Aula365" on student learning. This procedure helped us to test the null hypothesis that the means of two samples do not differ from each other, since the groups were independent, as shown in table 5 .

Table 5 Student $\mathbf{T}$ test to stop independent samples in the experimental and control group

\begin{tabular}{|c|c|c|c|c|c|c|}
\hline \multicolumn{7}{|c|}{ Experimental group } \\
\hline Description & Pos test & Pre test & $\begin{array}{c}\text { Dif. } \\
\text { Stockings }\end{array}$ & $\begin{array}{c}\mathrm{T} \\
\text { calculated }\end{array}$ & $\begin{array}{c}\text { T tab } \\
(58,0.05)\end{array}$ & $\mathrm{P}<0.05$ \\
\hline Average & 35.72 & 28.40 & \multirow{4}{*}{7.32} & \multirow{4}{*}{4.076} & \multirow{4}{*}{2.002} & \multirow{4}{*}{$\begin{array}{c}0.000 \text { (significant } \\
\text { test) }\end{array}$} \\
\hline Variance & 59.45 & 37.36 & & & & \\
\hline Dev. stand & 7.71 & 6.11 & & & & \\
\hline Sample & 30 & 30 & & & & \\
\hline \multicolumn{7}{|c|}{ Control group } \\
\hline Average & 20.08 & 20.30 & \multirow{4}{*}{-0.22} & \multirow{4}{*}{-1.147} & \multirow{4}{*}{2.002} & \multirow{4}{*}{$\begin{array}{c}0.884 \text { (non- } \\
\text { significant test) }\end{array}$} \\
\hline Variance & 33.92 & 33.72 & & & & \\
\hline Dev. stand & 5.82 & 5.81 & & & & \\
\hline Sample & 30 & 30 & & & & \\
\hline
\end{tabular}

Source: Pre test and post test of the experimental and control groups. 
In table 5, we observe that in the experimental group there is a statistically significant difference (mean difference $=7.32, \mathrm{P}<0.05$, tcalc $=4.076>=2.002$ ), in the average student learning scores before and after applying the program "Aula365" interactive television, this means that said educational television programs did influence improving student learning. However, in the control group we observe that there is no statistically significant difference (mean difference $=-0.22, \mathrm{P}>0.05$, tcalc $=-1,147<\mathrm{ttab}=2,002$ ), in the average student learning scores, this means that by The absence of such educational television programs did not influence the improvement of student learning.

Finally, in Figure 1 we can see graphically that the average student learning scores in the experimental group before and after applying the interactive television program “Aula365” (post test $=35.72$ points, pre test $=28.40$ points), yes they influenced student learning, however, in the control group as no stimulus was applied (post test $=20.08$ points, pre test $=20.30$ points), there was no difference in the average student learning scores.

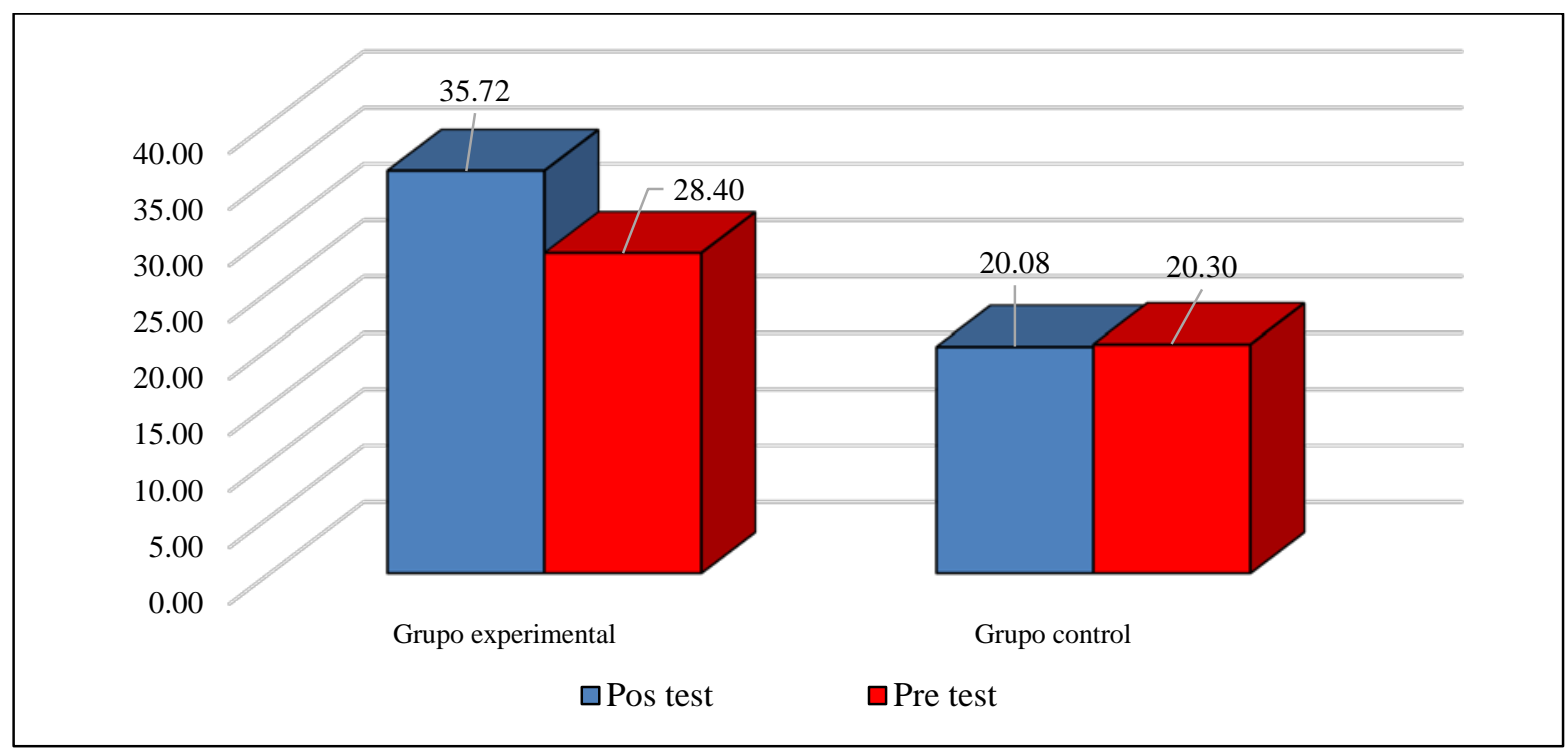

Figure 1 Comparison of pre test and post test averages, in the experimental and control group Source: Pre test and post test of the control and experimental group.

\section{Discussion}

From the findings found, we accept the research hypothesis that states that the interactive television program “Aula365" positively influences student learning, since in the pre-test the average was 28.40 and in the post-test of 35.72 points, whose difference in means was 7.32; however, in the control group in the pre-test an average of 20.30 was obtained and in the post-test of 20.08 (mean difference of -0.22). The results are compared with those obtained by Sanz (2019) 
who, when evaluating the influence of the television contents of "Prodigiosa: the adventures of Ladybug" and "Peppa Pig" in 403 students from 6 to 8 years, distributed in seven schools among audiences and deprived of 1 and 2 of primary education of the community of Madrid that observed these programs, found that they do exert an influence on the behaviors, values and attitudes of the children; both the positive and negative behaviors of the series influence the little ones when acquiring and developing values such as responsibility, social skills, conflict resolution, friendship, respect and acceptance of the other, in which the vast majority put into practice such behaviors, 77.17\%; However, the children of the private centers, who are the ones who visualize the series to a lesser extent, are the ones who have the least internalized values, $65.71 \%$, compared to $75.23 \%$ and $82.88 \%$ of the children public and concerted centers, respectively. Such research coincides with ours, in the sense that both programs positively or negatively influence children, in our case positively because only educational programs that managed to increase student learning were used as a stimulus.

For its part, Durán (2019) shows that of $100 \%$ of children who see cartoons, whether with negative or positive content, $28 \%$ of children do not exhibit aggressive behavior, while $72 \%$ of children They exhibit aggressive behavior. This research reinforces what was found in ours, by showing that the child learns what is in front of him or what the model wants him to learn.

Similar results were also found by Vásquez (2019), who, when experimenting with children between 7 and 9 years old, was able to show reality television shows that influence children, since children are imitators of the behaviors of the characters affecting their development. Another aspect to consider should also be whether children are exposed to television, alone or in the company of an adult or if the programs they watch is the one for their age. Faced with the above, Sanz (2019) found that in the majority they do not usually watch television accompanied, only $9.93 \%$ of 403 children who investigated, always see it in the company of an adult. $29.78 \%$ always see it alone, which is a relatively high percentage. $60.05 \%$ of children are in front of the TV screen sometimes alone and sometimes accompanied by an adult.

The results obtained in this research are also compared with Martinez \& Ureta (2019) who found that the television programs that students observe have a great influence on behavior and learning, since this leads to forgetting their tasks, not pay attention to the class by commenting on allusive topics to their favorite show; Likewise, it is reflected in their attitude, and the way they express themselves to their peers is violent and aggressive regardless of the well-being of their peers and the consequences that this can cause. Such results differ from ours. On the other hand, Alonso \& García (2016) in interactive digital television, conclude that the modern paradigm of digital convergence towards interactive television implies that the model is turning towards a transmedia communication 
that moves an integrated message through multiple media, languages and platforms.

The results obtained are contrasted with the research carried out by Asencio (2012) where he concludes that $100 \%$ of children who watch television and that most of their time is spent in front of a television, causes aggressive behaviors, in the same way they receive Negative attitudes and bad habits for its development. He also concludes that children prefer to watch more cartoons with violent content, than with educational programs and that television abuse has a negative influence on school performance. However, it is not entirely true when television is given a pedagogical value. On the other hand, educational and cultural television programs show us great advantages for achieving desired behavior as well as more solid learning, however, they are the most scarce in Latin America, because, on the one hand, they have a high cost, and usually they have very little audience (Berrú, 2007). Definitely, these contributions are based on the analysis criteria, which in the present investigation has been highlighted, since, in the local context of Chachapoyas, Amazonas-Peru region, there is no emphasis on television programs of a purely educational and cultural nature.

For these reasons, the research carried out, has given rise, to verify that television would be an excellent medium and a powerful tool in didactic and pedagogical matters if one knows how to use, as evidenced by the results of the present investigation that in the group Experimental, of 24.40 in the pre test, the television program “Aula365”, positively influenced learning at 35.72\%, making a clear difference.

\section{Conclusions}

The application of the interactive television program "Aula365" positively influenced the learning of children in the fourth grade of the primary level of the Educational Institution "Seminario Jesús María”, Chachapoyas, since an excellent learning scale was reached, rising from an average of 28.4 in the pre test to 35.7 points in the post test.

The application of the interactive television program "Aula365" positively influenced the learning of vocabulary comprehension through antonym recognition, since, from 5.8 points in the pre-test, it amounted to 8 average scores in the post-test.

The application of the interactive television program “Aula365” positively influenced learning related to verbal reasoning by recognizing synonyms, since, from 5.5 points in the pre-test, it reached 7.3 average scores in the post-test.

The application of the interactive television program "Aula365" positively influenced the learning of logical reasoning according to the child's similar 
reasoning, since, from 5.8 points in the pre-test, it amounted to 7.3 average scores in the post-test.

The application of the interactive television program "Aula365” positively influenced the learning of numerical reasoning through numerical series, since, from 5.8 points in the pre-test, it reached 7.4 average scores in the post-test.

There are significant differences in learning progress in the control and experimental groups; in the experimental group the difference was positive of 7.32 points and in the control group it was negative of -0.22 .

\section{References}

Alonso, M., \& García, M.J. (2016). Interactive digital television Experiences towards transmedia communication. International Journal of Communication, 35, 1-11. Retrieved from http://institucional.us.es/ambitos/? P = 2736

Asencio, D.M. (2012). Children's television programs and their influence on the initial education of the basic education center "Coronela Filomena Chávez" province Manabí Cantón Puerto López, 2012. (Undergraduate thesis, Santa Elena Peninsula State University). Retrieved from http://repositorio.upse.edu.ec/handle/46000/554

Bandura, A. (1984). Theory of social learning. Madrid, Spain: Espasa Calpe.

Berrú, M. (2007). Modeling and Simulation of the variables that condition the academic performance of the students of the third year of secondary school in the schools of the District of Tarapoto. (Undergraduate thesis, National University of San Martín). Retrieved from http://tesis.unsm.edu.pe/jspui/handle/11458/235

Criado, M.F., Pallares, J., \& Ascanio, Y.T. (2019). Children's television and its influence on the behavior and learning of children in the second grade " $A$ " of the Normal Superior School of Ocaña, Primary School. (Degree thesis; Superior Normal School of Ocaña). Retrieved from http://www.enso.edu.co/biblionline/archivos/2954.pdf

Chavez, A. (2004). Educational television or television to learn. Electronic magazine: Reason and word, 8(36). Retrieved from https://bit.ly/2tjx12P

Del Olmo, F. (1958). Rapid Test Barranquilla. New York: Psychological Corporation.

Díaz, I.Y., Enciso, R., González, S., Mendoza, R.A., \& Fonseca, M.E. (2019). Television and its influence on children: the case of an elementary school. Teaching and Research in Psychology, Special Number, 28-33. Retrieved from https://bit.ly/37Ric6y

Durán, M.C. (2019). Cartoons and behavior of children in the 2nd cycle in an initial education school, 2018. (Master's thesis, Universidad César Vallejo). Retrieved from http://repositorio.ucv.edu.pe/handle/UCV/29429

Martinez, J.A. \& Ureta, L.E. (2019). Children's programs and their influence on children's behavior. DGI - Journal of University Research of the Universidad Peruana Unión. Retrieved from http://repositorio.upeu.edu.pe/handle/UPEU/2379

Ñaupas, H., Mejía, E., Novoa, E., \& Villagómez, A. (2013). Methodology of scientific research and thesis preparation (3rd ed.) Lima, Peru: San Marcos.

Pijamasurf. (2009). Studies prove serious effects of TV on the health of children and adolescents [Datafile]. Retrieved from https://bit.ly/2Oh5tlR

Ruiz, Y.M. (2010). Vicarious learning: educational implications in the classroom. Digital magazine for teaching professionals, Topics for education, 1(10), 1-6. Retrieved from https://www.feandalucia.ccoo.es/docu/p5sd7465.pdf 
Sanz, M. (2019). The influence of the children's television content of "Prodigiosa: the adventures of Ladybug" and "Peppa Pig" in 1st and 2nd primary education (PhD thesis, Universidad Complutense de Madrid). Retrieved from https://bit.ly/2OlLCSR

Vásquez, V.M. (2019). TV shows "reality show" and its influence on children from 7 to 9 years of the Cooperativa Unión de Bananeros, block 2 mz8 of Guasmo Sur, Guayaquil 2018. (Bachelor thesis; University of Guayaquil). Retrieved from https://bit.ly/2UcW9DA

World Summit Award -WSA. (2013). Classroom365. [Message in a blog]. Retrieved from https://bit.ly/37QvJvm 